\title{
A New Route to Enhance the Light-Harvesting Capability of Ruthenium Complexes for Dye-Sensitized Solar Cells**
}

\author{
By Chia-Yuan Chen, Shi-Jhang Wu, Jheng-Ying Li, Chun-Guey Wu,* Jian-Ging Chen, and \\ Kuo-Chuan Ho
}

Dye-sensitized solar cells (DSCs) have been explored for more than a decade for realistic photovoltaic applications owing to their high conversion efficiency and low cost. ${ }^{[1]}$ Molecular engineering of the sensitizers to achieve high photovoltaic performance and long-term device stability is one of the critical strategies. Since the first high-efficiency ruthenium-based sensitizer, cis-di(thiocyanato)-bis-(2,2'-bipyridyl)-4,4'-dicarboxylate ruthenium(II) (N3), reported by Grätzel and coworkers in $1993,{ }^{[2]}$ various structural modifications have been performed to improve the molar extinction coefficient of the sensitizers. It was found that elongating the conjugation length of the anchoring or ancillary ligand is the best route ${ }^{[3-5]}$ although it may come up against the problem of solubility, which is not only a critical point for dye preparation, purification, and identification but also one of the crucial factors for the photovoltaic performance of DSCs. ${ }^{[6]}$ Nevertheless, it is essential to enhance the light-harvesting capacity and at the same time maintain the desirable solubility of dyes to be used in DSCs. Here we report the synthesis and performance of a new well-designed ruthenium complex, SJW-E1 (cis-di(thiocyanato)-4,4'-di(octylethylenedioxythienyl)-2,2'-bipyridine4,4'-dicarboxylate-2,2'-bipyridine ruthenium(II)), which showed high light-harvesting capacity and good solubility in organic solvents. Another new ruthenium complex, denoted CYC-B3 (cis-di(thiocyanato)-4,4'- di(octylthienyl)-2,2'-bipyridine-4,4'-dicarboxylate-2,2'-bipyridine ruthenium(II)), was also prepared not only to explore the effect of thiophene moieties but also for comparison with SJW-E1 to investigate the impact of the ethylenedioxy groups on the physicochemical properties and performance of the dye molecules.

The structures of SJW-E1 and CYC-B3, which incorporate $\alpha$-octyl-ethylene-dioxythiophene (O-EDOT) and octyl-thio-

[*] Prof. C.-G. Wu, C.-Y. Chen, S.-J. Wu, J.-Y. Li Department of Chemistry, National Central University Jhong-Li, Taiwan 32001 (Taiwan)

E-mail: t610002@cc.ncu.edu.tw

Prof. K.-C. Ho, J.-G. Chen

Department of Chemical Engineering, National Taiwan University Taipei 10617 (Taiwan)

[**] This work was financially supported by the National Science Council, Taiwan, under grant number NSC-95-2113-M-008-011-MY3. Supporting Information (detailed synthetic procedures and structure characterizations of the new ruthenium complexes, $\mathrm{TiO}_{2}$ electrode preparation, DSC device fabrication and performance tests, as well as device-related measurements) is available online from Wiley InterScience or from the authors. phene-substituted bipyridine, respectively, as an ancillary ligand, are shown in Figure 1. The synthetic details and structure characterizations are provided in the Supporting

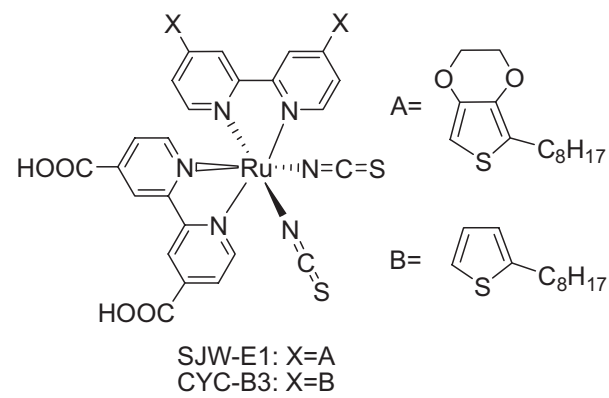

Figure 1. Molecular structures of SJW-E1 and CYC-B3.

Information. The frontier orbitals of SJW-E1 and CYCB3 obtained with a semiempirical ${ }^{[7]}$ calculation method (ZINDO/1) were illustrated in Figure 2. The results showed that both the highest-occupied molecular orbitals (HOMOs) and lowest-unoccupied molecular orbitals (LUMOs) of SJWE1 and CYC-B3 have similar localizations: The HOMOs and LUMOs are contributed from the metal center with the NCS ligands and the anchoring ligand (4,4'-dicarboxylate-2,2'-bipyridine), respectively. In other words, the two dyes have a similar metal-to-ligand charge transfer (MLCT) excitation. In addition, the same anchoring group in the two dyes provides a comparable interfacial electron transfer process. Therefore the efficiency of the dyes will depend primarily on the absorption coefficients of their MLCT bands.

The electronic absorption spectra of the dye molecules measured in dimethylformamide (DMF) (Fig. 3a) display that the lower energy MLCT band for SJW-E1 is centered at $546 \mathrm{~nm}$ with a molar absorption coefficient of $18.7 \times 10^{3} \mathrm{M}^{-1} \mathrm{~cm}^{-1}$. This value is higher than those of the dyes CYCB3 $\left(15.7 \times 10^{3} \mathrm{M}^{-1} \mathrm{~cm}^{-1}\right.$ at $\left.544 \mathrm{~nm}\right)$ and N3 $\left(14.5 \times 10^{3} \mathrm{M}^{-1} \mathrm{~cm}^{-1}\right.$ at $530 \mathrm{~nm})$. The higher light-harvesting capacity of SJWE1 dye compared with CYC-B3 and N3 dyes was attributed to the ethylenedioxy pendent group of EDOT, which could provide a supplementary electron-donating ability and $\pi$-conjugation to the thiophene moiety. Although the light-harvesting ability of SJW-E1 is still lower than that of CYC-B1 (cis-di(thiocyanato)-4,4'-di(octylbithienyl)-2,2'-bipyridine-4,4'dicarboxylate-2,2'-bipyridine ruthenium(II)), which we re- 


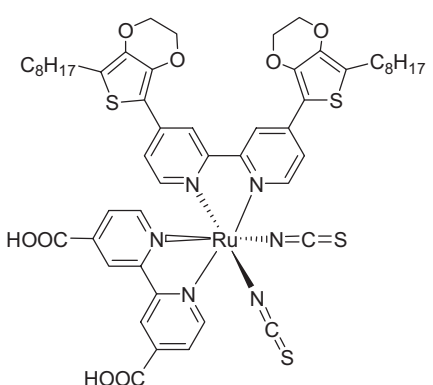

SJW-E1

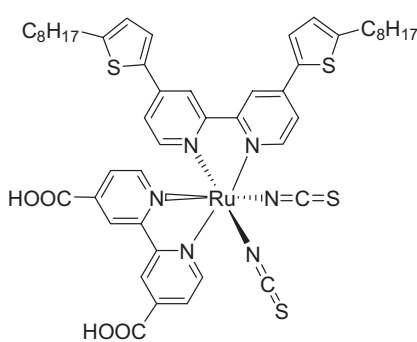

CYC-B3

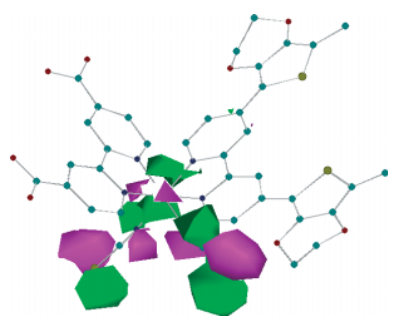

HOMO

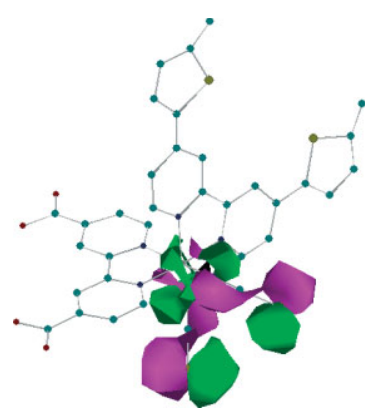

HOMO

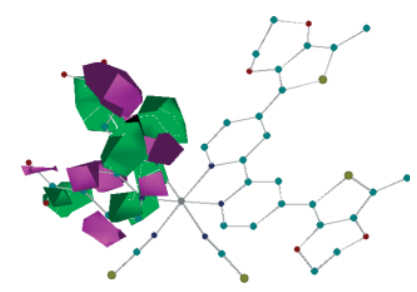

LUMO

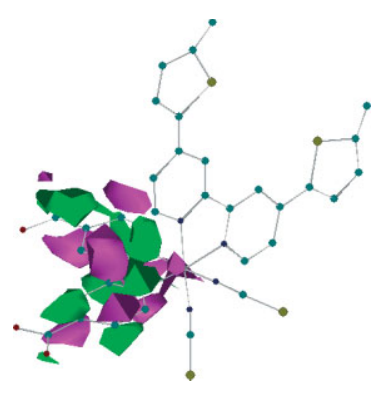

LUMO

Figure 2. Graphical representation of the frontier orbitals of SJW-E1 and CYC-B3. Atoms in red, yellow, green, blue, and gray correspond to oxygen, sulfur, carbon, nitrogen, and ruthenium, respectively.

ported previously, ${ }^{[8]}$ it is close to that of HRS-1 (cis-di(thiocyanato)-4,4'-di(hexylthienylvinyl)-2,2'-bipyridine- $4,4^{\prime}$-dicarboxylate-2, $2^{\prime}$-bipyridine ruthenium(II)), ${ }^{[9]}$ which uses thienylvinyl-conjugated bipyridine as an ancillary ligand. The electronic absorption spectra (in transmission mode) of SJWE1, CYC-B3, and N3 assembled on the $\mathrm{TiO}_{2}$ thin films (Fig. 3b) combined with the absorption coefficients of the dyes in solution revealed that the $\mathrm{TiO}_{2}$ thin films adsorbed a similar amount of SJW-E1, CYC-B3, and N3 molecules. Here we suppose that the absorption coefficients of the dye molecules in solution and adsorbed on the surface of $\mathrm{TiO}_{2}$ are the same, and that the practical $\mathrm{TiO}_{2}$ films $(20 \mu \mathrm{m}$ thickness $)$ used in the device have the same behavior as the thin $(2.4 \mu \mathrm{m})$ $\mathrm{TiO}_{2}$ films used for the absorption measurement. This result then suggests that the size of the ruthenium complexes used in this study will not affect the number of dye molecules assembled on the $\mathrm{TiO}_{2}$ electrodes. Therefore we could expect a SJW-E1-sensitized solar cell to have a better photon-to-current conversion efficiency than a N3-sensitized solar cell. Note here that the absorption intensity of CYC-B3 is lower than for the other two dyes, probably owing to the lower solubility of CYC-B3.

The incident photon-to-current conversion efficiency (IPCE) spectra of SJW-E1-, CYC-B3-, and N3-sensitized solar cells were illustrated in Figure 4a. The broad bands cover almost the entire visible spectrum from 350 to $700 \mathrm{~nm}$ with the maxima of $72.6 \%$ at $550 \mathrm{~nm}, 64.1 \%$ at $520 \mathrm{~nm}$, and $69.6 \%$ at $500 \mathrm{~nm}$ for SJW-E1-, CYC-B3-, and N3-sensitized solar cells, respectively. The corresponding current-voltage $(I-V)$ characteristic curves of the solar cells under AM 1.5 sunlight illumi- nation $\left(100 \mathrm{~mW} \mathrm{~cm}^{-2}\right)$ are displayed in Figure $4 \mathrm{~b}$ and the detailed device parameters are listed in Table 1. The IPCE values of the cells are slightly lower than the short-circuit photocurrent density $\left(J_{\mathrm{sc}}\right)$ appearing in the $I-V$ characteristic curve because the light intensities used to measure these two data are not the same (the incident light employed in IPCE measurement is not continuous and the intensity is lower). The $I-V$ curve revealed that the CYC-B3-sensitized solar cell has $J_{\mathrm{sc}}=15.7 \mathrm{~mA} \mathrm{~cm}^{-2}, 0.669 \mathrm{~V}$ open circuit potential $\left(V_{\mathrm{oc}}\right)$ and 0.705 fill factor (ff), yielding power conversion efficiencies $(\eta)$ of $7.39 \%$, which is $87.8 \%$ of the N3-sensitized solar cell, which has $\eta=8.42 \%$ under the same cell fabrication and measuring procedures as used in our laboratory. The SJW-E1sensitized solar cell gave a very high photocurrent density of $21.6 \mathrm{~mA} \mathrm{~cm}^{-2}$ and $\eta=9.02 \%$, which is $22 \%$ higher than that of the CYC-B3-sensitized cell. The significant increase in $\eta$ value for SJW-E1- compared to CYC-B3-sensitized solar cells revealed the important role of the EDOT moiety in the ancillary ligand of the ruthenium complex. Nevertheless, we found that the SJW-E1-sensitized cell has a relatively lower fill factor compared to N3- and CYC-B3-sensitized cells. This may due to the defects of the SJW-E1 monolayer on the $\mathrm{TiO}_{2}$ elec-

Table 1. Photovoltaic performance of DSCs with different sensitizers under AM 1.5 simulated sunlight $\left(100 \mathrm{~mW} \mathrm{~cm}^{-2}\right)$ illumination.

\begin{tabular}{lcccc}
\hline Sensitizer & $J_{\text {sc }}\left[\mathrm{mA} \mathrm{cm}^{-2}\right]$ & $V_{\text {oc }}[\mathrm{mV}]$ & $\mathrm{ff}$ & $\eta[\%]$ \\
\hline SJW-E1 & 21.6 & 669 & 0.626 & 9.02 \\
CYC-B3 & 15.7 & 669 & 0.705 & 7.39 \\
N3 & 18.4 & 690 & 0.664 & 8.42 \\
\hline
\end{tabular}



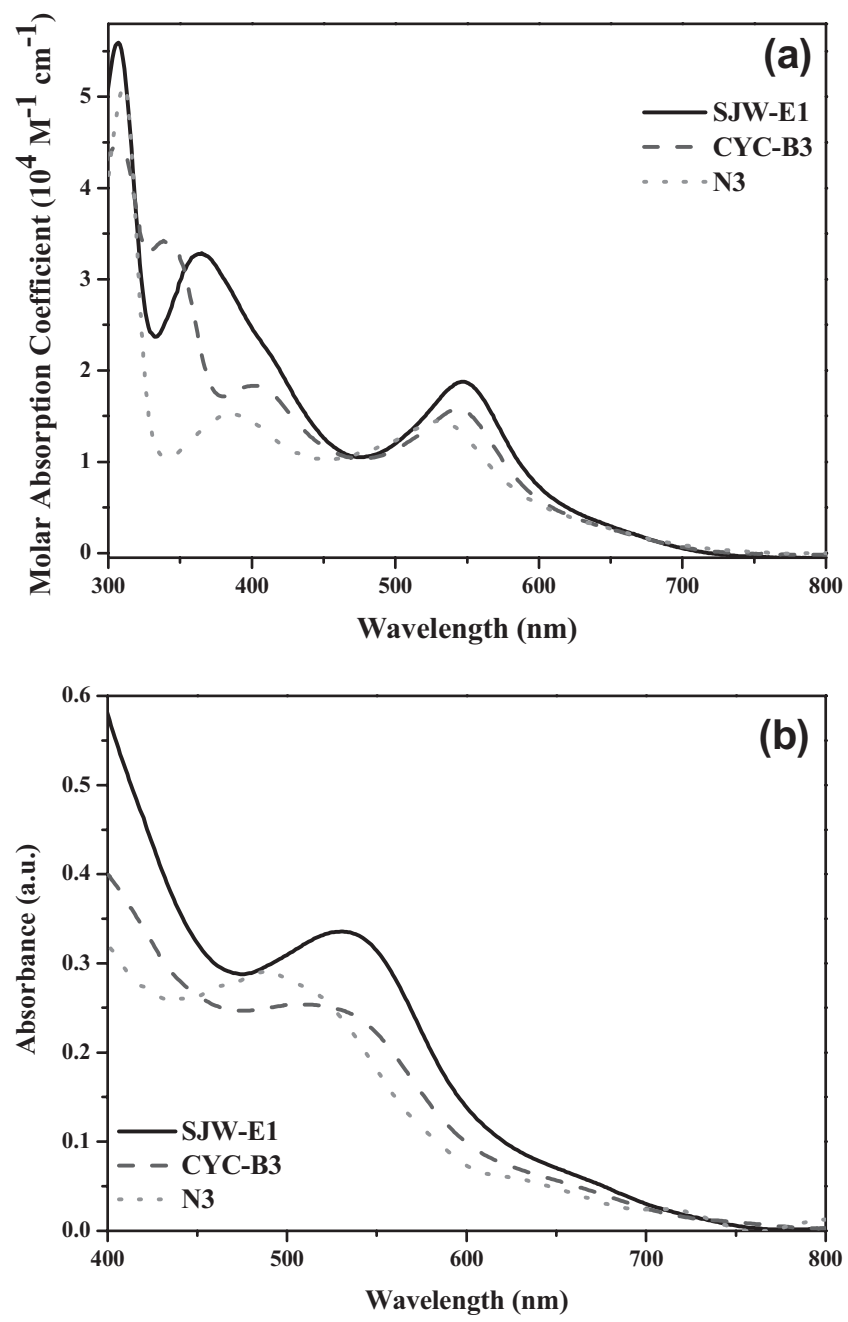

Figure 3. a) Electronic absorption spectra of SJW-E1, CYC-B3, and N3 measured in DMF. b) The visible absorption spectra of different dyes anchored onto a $2.4 \mu \mathrm{m}$ thick transparent nanocrystalline $\mathrm{TiO}_{2}$ film.

trode (among other possibilities related to the device fabrication) because we also found that the dark current of the SJWE1-based cell (Fig. 4c) is higher than the cells based on the other two dyes. The use of appropriate co-adsorbents or solvent in the dye assembly process may be able to fix the defects and enhance the performance of SJW-E1. This work is in progress and the results will be reported elsewhere.

Photoelectrochemical impedance spectroscopy (PEIS) is generally used to investigate the lifetime $\tau$ of the electron on the $\mathrm{TiO}_{2}$, which will be affected by the photo-oxidized sensitizers and electrolyte. ${ }^{[10,11]}$ The measurements were performed under open-circuit conditions and AM 1.5 simulated sunlight illumination $\left(100 \mathrm{~mW} \mathrm{~cm}^{-2}\right)$. The results are displayed in the form of a Bode phase plot, as shown in Figure 5. The $\tau$ values for SJW-E1-, CYC-B3-, and N3-sensitized cells calculated from the intermediate-frequency regime of the plot are 9.8, 6.8 , and $12.4 \mathrm{~ms}$, respectively. The N3-sensitized cell has quite a high $\tau$ value, especially compared to CYC-B3. This is perhaps the reason why N3 dye has a high efficiency despite its
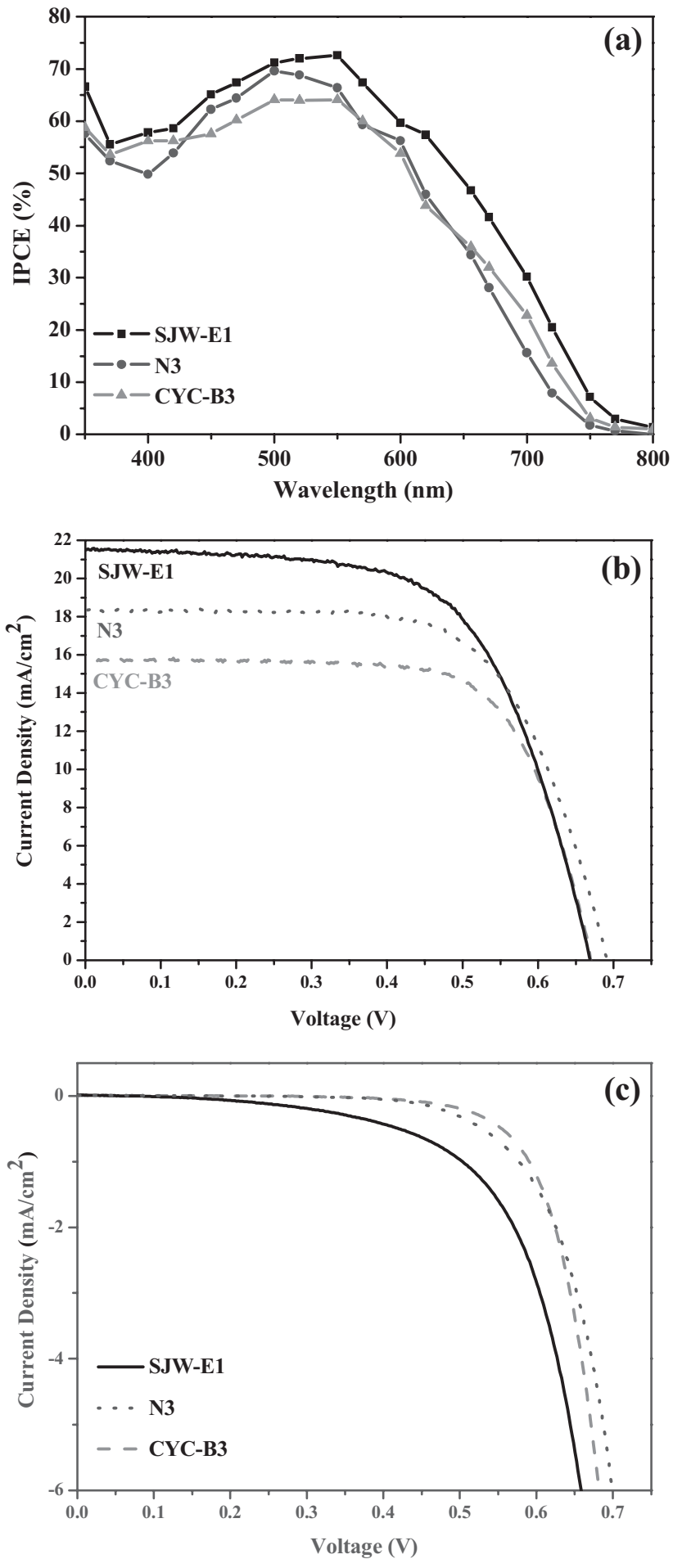

Figure 4. a) The typical photocurrent action spectra of the photovoltaic devices with different sensitizers. b) Characteristic current density-voltage curves of photovoltaic devices measured under AM 1.5 simulated sunlight illumination $\left(100 \mathrm{~mW} \mathrm{~cm}{ }^{-2}\right)$. c) Current density-voltage curves of photovoltaic devices measured in the dark. (Thickness of $\mathrm{TiO}_{2}: 20 \mu \mathrm{m}$, cell active area (tested with mask): $0.16 \mathrm{~cm}^{2}$ ).

moderate light-absorption ability. Surprisingly, the SJW-E1sensitized cell has a distinctly longer $\tau$ value than the CYC- 


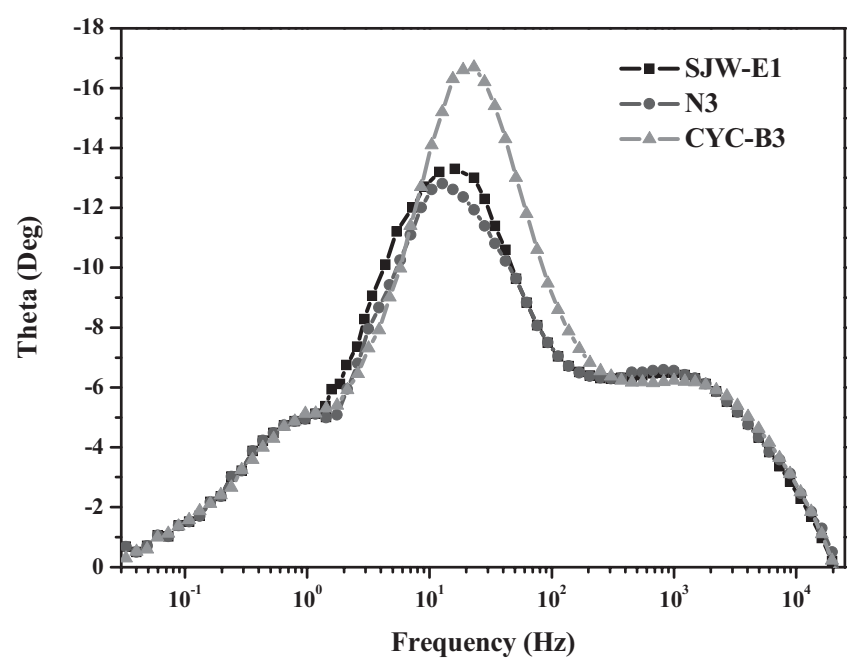

Figure 5. Photoelectrochemical impedance spectra of SJW-E1-, CYC-B3-, and N3-sensitized cells in the form of a Bode phase plot. (Measured under open-circuit conditions and AM 1.5 simulated sunlight illumination $\left.\left(100 \mathrm{~mW} \mathrm{~cm}^{-2}\right)\right)$.

B3-sensitized cell. The dissimilarity in the $\tau$ values between these two cells also points out the special function of the ethylenedioxy pendent on the ancillary ligand of SJW-E1; in other words, the novel properties of the EDOT moiety.

EDOT has the unique combination of strong electron donation ability and self-structuring effects related to the intramolecular noncovalent interactions between oxygen and sulfur. This intramolecular interaction also affects the structure and electronic properties of conjugated molecules incorporating the EDOT unit. Consequently, EDOT is a good building block for the synthesis of functional $\pi$-conjugated systems such as fluorophores and push-pull chromophores. ${ }^{[12]}$ Therefore, in the case of long substituents on the bipyridine of the ancillary ligand, a larger $\mathrm{TiO}_{2}$ surface will be needed to avoid steric hindrance. Incorporating EDOT moieties on bipyridine can increase the conjugation length of the ancillary ligand without increasing the size of the ruthenium complex. The strongly electron-donating ether group on EDOT can avoid the intramolecular electron-hole recombination of SJW-E1 and increase the lifetime of the electron on $\mathrm{TiO}_{2}$ (reducing the possibility of recombination of the electrons on $\mathrm{TiO}_{2}$ with the holes on the complex dye). The ether group also makes the $\alpha$ and $\alpha^{\prime}$ positions of the EDOT very reactive; further structure modification can be easily carried out, such as adding a alkyl group to prevent the water-induced desorption of the adsorbed dye molecules. ${ }^{[13]}$ Moreover, the ether group in the EDOT may be also able to interact with the $\mathrm{Li}^{+}$to increase the dye regeneration rate, as found in K60 (cis-di(thiocyanato)-4,4'-bis(2-(4-(1,4,7,10-tetraoxyundecyl)phenyl)ethenyl)2,2'-bipyridine-4,4'-dicarboxylate-2,2'-bipyridine ruthenium (II) $),{ }^{[14]}$ although we do not have any evidence.

In conclusion, we have prepared two new ruthenium complex dyes, SJW-E1 and CYC-B3, with very high photon-tocurrent conversion efficiency. The difference in the perfor- mance of these dye-sensitized DSCs demonstrates that molecular engineering of the ancillary ligand of the ruthenium complexes to achieve higher performance could be expanded from one-dimensional extension of the conjugation length to two-dimensional conjugation enhancement and functional group substitution.

\section{Experimental}

Synthesis of SJW-E1 and CYC-B3: The detailed synthetic procedures and structure characterizations of these two new ruthenium complexes can be found in the Supporting Information. The structure of the ligands was identified by ${ }^{1} \mathrm{H}$ NMR spectra. The structure of the complexes was also confirmed by ${ }^{13} \mathrm{C}$ NMR, mass spectrum, and elemental analysis, as well as ${ }^{1} \mathrm{H}$ NMR.

Physicochemical Studies: ${ }^{1} \mathrm{H}$ NMR and ${ }^{13} \mathrm{C}$ NMR spectra were recorded with a Bruker $500 \mathrm{MHz}$ NMR spectrometer in $d_{6}$-DMSO (dimethyl sulfoxide). Fast atom bombardment mass sprectometry (FAB-MS) spectra were obtained using JMS-700 HRMS. UV-vis spectra were measured using a Cary 300 Bio spectrometer. Elemental analyses were carried out with a Heraeus CHN-O-S Rapid-F002 analysis system. Molecular orbitals and geometry optimizations for free sensitizers were computed using the Hyperchem7 program. Geometry optimizations were calculated with ZINDO/1 parameter set. The overlap weighting factors were set as default. Detailed procedures for DSC device fabrication and performance testing can be found in the Supporting Information.

Received: May 8, 2007

Revised: August 20, 2007

Published online: October 31, 2007

[1] B. O’Regan, M. Grätzel, Nature 1991, 353, 737.

[2] M. K. Nazeeruddin, A. Kay, L. Rodicio, R. Humphry-Baker, E. Müller, P. Liska, N. Vlachopoulos, M. Grätzel, J. Am. Chem. Soc. 1993, 115,6382 .

[3] P. Wang, S. M. Zakeeruddin, J.-E. Moser, R. Humphry-Baker, P. Comte, V. Aranyos, A. Hagfeldt, M. K. Nazeeruddin, M. Grätzel, Adv. Mater. 2004, 16, 1806.

[4] S. R. Jang, C. Lee, H. Choi, J. J. Ko, J. Lee, R. Vittal, K. J. Kim, Chem. Mater. 2006, 18, 5604

[5] D. Kuang, S. Ito, B. Wenger, C. Klein, J. E. Moser, R. Humphry-Baker, S. M. Zakeeruddin, M. Grätzel, J. Am. Chem. Soc. 2006, 128, 4146.

[6] a) C. Y. Chen, H. C. Lu, C. G. Wu, J. G. Chen, K. C. Ho, Adv. Funct. Mater. 2007, 17, 29. b) M. K. Nazeeruddin, F. D. Angelis, S. Fantacci, A. Selloni, G. Viscardi, P. Liska, S. Ito, B. Takeru, M. Grätzel, J. Am Chem. Soc. 2005, 127, 16835.

[7] E. Figgemeier, V. Aranyos, E. C. Constable, R. W. Handel, C. E. Housecroft, C. Risinger, A. Hagfeldt, E. Mukhtar, Inorg. Chem. Commun. 2004, 7, 117.

[8] C. Y. Chen, S. J. Wu, C. G. Wu, J. G. Chen, K. C. Ho, Angew. Chem. Int. Ed. 2006, 45, 5822 .

[9] K. J. Jiang, N. Masaki, J. B. Xia, S. Noda, S. Yanagida, Chem. Commun. 2006, 2460.

[10] S. Ito, M. K. Nazeeruddin, P. Liska, P. Comte, R. Charvet, P. Péchy, M. Jirousek, A. Kay, S. M. Zakeeruddin, M. Grätzel, Prog. Photovoltaics: Res. Appl. 2006, 14, 589.

[11] M. Adachi, M. Sakamoto, J. Jiu, Y. Ogata, S. Isoda, J. Phys. Chem. B 2006, 110, 25251

[12] J. Roncali, P. Blanchard, P. Frère, J. Mater. Chem. 2005, 15, 1589.

[13] P. Wang, S. M. Zakeeruddin, J. E. Moser, M. K. Nazeeruddin, T. Sekiguchi, M. Grätzel, Nat. Mater. 2003, 2, 402.

[14] D. Kuang, C. Klein, S. Ito, J. E. Moser, R. H. Baker, S. M. Zakeeruddin, M. Grätzel, Adv. Funct. Mater. 2007, 17, 154. 